\title{
Obsessive compulsive beliefs and metacognitions in patients with obsessive compulsive disorder
}

\author{
Nitin Anand ${ }^{1}$ Mahendra Prakash Sharma ${ }^{2}$ \\ ${ }^{1}$ Assistant Professor, Department of Clinical Psychology, National Institute of Mental Health and Neuro Sciences, \\ (NIMHANS), Bangalore. \\ ${ }^{2}$ Professor and Head, Department of Clinical Psychology and Consultant, Behaviour Medicine Unit, National \\ Institute of Mental Health and Neuro Sciences, (NIMHANS), Bangalore. \\ E-mail - nitinanand19800@gmail.com (Nitin Anand). Tel - 080-2699 5886.
}

\begin{abstract}
Background: Obsessive Compulsive Disorder (OCD) is a debilitating disorder having a lifetime prevalence of $1 \%$ to $3 \%$. A significant number of advances have occurred in understanding the development and treatment of OCD, however, only close to $50 \%$ individuals with OCD respond to current interventions. Evaluation of underlying cognitive processes (metacognitive processes) appears to hold promise for advancing treatment outcomes for those who do fully identify having dysfunctional cognitive beliefs. The objective was to assess cognitive and metacognitive beliefs underlying obsessive compulsive behavior.

Methodology: Twenty patients with obsessive compulsive disorder were compared with non-patient control sample of 20 participants on measures of obsessive beliefs and metacognitions. The clinical sample was also assessed on measures of obsessive compulsive symptom severity

Results: A significantly higher occurrence of obsessive compulsive beliefs and metacognitions in clinical sample and positive correlations between obsessive compulsive symptom severity and cognitive and metacognitive belief domains. In addition, obsessive compulsive beliefs were significantly correlated with certain specific metacognitive domains.

Conclusions: The findings suggest that those with OCD endorsed the presence of metacognitive beliefs. The metacognitive beliefs could be considered as underlying motivational process which appears to maintain obsessive compulsive behaviours. This preliminary observation requires further extensive evaluation.
\end{abstract}

Keywords: Obsessive compulsive beliefs, Metacognitions, Obsessive compulsive disorder

(Paper received $-1^{\text {st }}$ August 2016, Peer review completed $-30^{\text {th }}$ August 2016, Accepted $-2^{\text {nd }}$ September 2016)

\section{INTRODUCTION}

Obsessive compulsive disorder (OCD) is a chronic and debilitating psychiatric disorder. It is the fourth most common psychiatric disorder with a lifetime prevalence of $1-3 \%$ in the community [1-2] and is recognized as one of the leading causes of psychiatric morbidity and disability worldwide [3-4].

Although, major advances have occurred in therapeutic treatment of OCD, still approximately $40 \%$ to $60 \%$ OCD patients do not improve sufficiently with adequate and multiple trials of treatment with SRIs both in short-term trials and at long-term follow-up [5-7]. Patients who respond to medications achieve approximately $40 \%$ reduction in their symptoms [8-10]. CBT is currently a well established first line treatment for OCD, with long-term efficacy comparable to that of SRIs [11-12]. However, at completion of intervention program, CBT incorporating EX/RP leads to a higher reduction of symptoms; ranging from $70 \%$ to $90 \%$ [13-14] although refusal rate is $25 \%$ [15] and $15 \%$ to $20 \%$ patients drop-out from CBT [11,1617]. 
The limitations associated with available cognitive-behavioral and pharmacological interventions, absence of clarity on etiology of OCD and growing research interest in cognitive appraisal models and belief domains of OCD have been the propellants towards development of cognitive frameworks and associated therapies. The motivation to develop newer frameworks appears to aim towards enhancement of the degree of global improvement for patients with OCD.

Several cognitive models have proposed obsessive compulsive beliefs domains and the appraisal of intrusive thoughts in the etiology of obsessive compulsive symptoms [18]. Faulty appraisals of intrusive thoughts and beliefs about thoughts are considered to be significant in development of obsessions and compulsions. Salkovskis suggested that individuals with OCD tend to experience inflated sense of responsibility and fear of blame for occurrence of harm to others and to self [19-20]. To reduce the likelihood of occurrence of harm, to minimize danger/risk to others/self and to decrease sense of responsibility and blame, compulsive behaviours are performed.

The cognitive models proposed by Rachman [21-22] Purdon and Clark [23] and Wells [24-25] highlight the significance of negative appraisals of intrusive thoughts as underlined by Salkovskis. However, here a significant focus is placed on beliefs about thoughts and thought process (Metacognitive Processes). The metacognitive models hold that metacognitive beliefs are beliefs about thoughts and thought process; which are central to dysfunctional cognitive processes that lead to OCD symptoms. The beliefs that thoughts are nearly equivalent to actions (Thought Action Fusion) or occurrence of thoughts can influence events (Thought-Event Fusion) have been found to be elevated in patients with predominant obsessions [26-27]. Less control of negative intrusive thoughts and higher distress has been reported in obsessional patients [28]. The significance and danger of cognitive intrusions, the need to control thoughts and/ or to perform rituals to control them and thought action fusion phenomena are understood as important predictors in causation of obsessive compulsive symptoms [24-25, 29-30].

In patients with $\mathrm{OCD}$, when cognitive intrusions occur, they activate metacognitive beliefs which initiate processes to know meaning or importance of occurrence of thoughts. This metacognitive activation in turn influences the cognitive processes, i.e., appraisal of thoughts and degree of irrationality of beliefs, triggering behavioural rituals and cognitive responses aimed to control the thoughts/ minimize danger associated with thoughts [24].

Self Regulatory Executive Function Model can be applied to explain the repetitive thoughts experienced in individuals with OCD [31]. It is suggested that as limited resources of information processing become focused on internal events including thoughts, the internal events/ processes dictate the attempts to alter the emotional experiences and behavior rather than objective experience external to self [31]. As enhancement to the existing cognitive theories, metacognitive processes have been emphasized.

Early work in experimental psychopatholgy on self-focused attention (like Self-consciousness) appears to be the forerunner of the evolving interest in metacognitive processes and OCD. It has been postulated that self-focussed attention leads to emergence of anxiety [32]. If self- focused attention leads to awareness of distressing or threatening thoughts or emotions, then negative affect will emerge as a consequence. Elevated levels of self-consciousness have been reported across numerous forms of psychopathology inclusive of anxiety and depression [33]. Likewise, facilitation of self-focused attention among phobic subjects during exposure exercises leads to intensification of fearful responses [34-35]. Self-focussed attention in OCD may involve excessive awareness or attention to thoughts. In addition, to differences in cognitive appraisal of intrusive thoughts and specific beliefs about occurrence of thoughts, a fundamental dimension in psychopathology of OCD may be caused by excessive awareness about intrusive thoughts.

Investigation by Cartwright-Hatton \& Wells [36] reported that patients with OCD and Generalized anxiety disorder (GAD) differed significantly from emotional disorder controls (nonanxiety) and normal controls on the dimensions of uncontrollability of thoughts and danger and negative beliefs about thoughts. Cognitive Self- Consciousness (CSC) was the only dimension which differentiated patients of OCD from GAD. Patients with OCD scored significantly higher than GAD patients on the CSC [37]. Findings of this study extend the original research observations on CSC by Cartwright-Hatton \& Wells 
[36] which suggested excessive attentional focus on thoughts may influence the manner of information processing by obsessive individuals.

CSC is understood as the tendency to foucs excessive attention and monitoring of one's thought processes. CSC on the whole appears to increase significance of thoughts, which tends to increase likelihood for negative thought appraisals and lead to emergence of over-importance of thoughts and beliefs [37]. The metacognitive process of CSC may be helpful to explain the difficulties of people in dismissing common negative thought intrusions, which are easily processed or ignored by majority of the population [38].

Further, it is proposed that CSC may be associated with cortical-striatal dysfunction and deficit in nonconscious processing gating; which result in processing of unimportant stimuli consciously and inefficiently. CSC has been theorized to contribute significantly towards pathophysiology of OCD [39]. To extend exploration of relationship between striatal functioning and CSC, a study revealed that higher levels of CSC was associated with poor performance on implicit procedural learning and superior performance on pattern recognition task. The superior performance on recognition of embedded patterns indicates that OCD patients rely excessively on explicit learning to perform tasks that would be better achieved without explicit awareness. The findings suggest that individuals with OCD rely excessively on explicit learning strategies for a majority of tasks and greater procedural learning impairment was evident in hoarding subgroup of OCD patients [40]. The explanations proposed by cognitive models [41-42] and neurobiological theories $[39,43]$ have gained wider acceptance towards development and maintenance of the disorder.

On the basis of available cognitive theories and metacognitive model proposed by Wells \& Mathews [2425] and research findings of Cartwright-Hatton and Wells [36],we believe that further evaluation of metacognitive beliefs in conjunction with obsessive compulsive beliefs could provide us with insights about specific cognitive profile of OCD. In the present study, we aimed to investigate, obsessive compulsive beliefs and metacognitive beliefs and their inter-relationship in patients with OCD and non-patient controls.

\section{METHODOLOGY}

\section{Sample and study design}

The study comprised of two groups and was cross-sectional in nature with a case-control design. A clinical sample $(n=20$, age mean $=27.50$, S.D._7.48) of patients with a diagnosis of obsessive compulsive disorder as per ICD 10 criteria (F42.0) was selected from psychiatric services of NIMHANS, Bangalore, India. Patients with history of comorbid anxiety disorders, psychosis, bipolar disorder, current psychoactive substance dependence, and those who had received behavioural or cognitive behavioral psychotherapy in the past were excluded. A non-patient control sample $(n=20$, mean $=28.15$, S.D._9.29), was selected through the snowballing technique and screened on the General Health Questionnaire (GHQ) [44-45]. Participants scoring above the cut off were excluded. Both groups responded to Obsessional Beliefs Questionnaire (OBQ-44) \& Metacognitions Questionnaire (MCQ-30). In addition, OCD patients were assessed on Yale- Brown Obsessive Compulsive Scale (Y-BOCS). This study was approved by the NIMHANS Ethics Committee. Written informed consent for participation was obtained from participants. All measures were individually administered and the order of administration was kept constant.

\section{Measures}

Yale- Brown Obsessive Compulsive Scale (Y-BOCS) [46] is a 10-item clinician administered scale which aims to assess the symptom severity of obsessions and compulsions for OCD patients. 5 items assess time spent, interference, distress, resistance and degree of control of obsessions and 5 assess similar dimensions of compulsions. Inter-rater reliability for instrument is excellent $(r=0.98)$. In addition, internal consistency is good with a cronbach alpha of .89 for the total scale [47]. 
Obsessional Beliefs Questionnaire (OBQ-44) [48] is a 44 item self-administered questionnaire, which aims to assess the belief domains considered to be significant in the etiology of OCD. Each item is rated on a seven point scale by participants where they choose a number which matches the answer that best describes how they think. The belief domains assessed included (1) Responsibility and Threat estimation, (2) Perfectionism and Intolerance for uncertainty, and (3) Importance and Control of thoughts. It has showed a good internal consistency with cronbach alphas of $0.93,0.93$ and 0.90 for the three belief domains [49].

MetaCognitions Questionnaire (MCQ-30) [50] is a 30 item self-administered questionnaire which aims to assess several metacognitive belief domains of such as (1) positive beliefs ("Worrying helps me avoids problems in the future"), (2) Negative Beliefs about uncontrollability and danger of thoughts ("My worrying is dangerous for me"), (3) cognitive confidence ("I have a poor memory"), (4) Need for control ("its terrible to think about certain thoughts"), (5) cognitive self-consciousness ("I think a lot about my thoughts"). All items are scored on a four point scale by participants where they choose a number which matches the answer that best describes how they think. MCQ shows good internal consistency with cronbach alphas for subscales ranging from 0.72 to 0.89 . The test-retest reliability was also good with coefficients of 0.75 for the total scale and 0.59 to 0.87 for subscales [50].

\section{STATISTICAL ANALYSIS}

Descriptive statistics inclusive of mean and standard deviation were utilized for analyzing data focusing on the sociodemographic details. The collected study data was also utilized for inferential statistics in the form of t-test for drawing comparative findings among the clinical and non-clinical sample across the measures of obsessive beliefs and metacognitions. Pearson correlation analysis was used for evaluation of association between obsessive compulsive symptomatology, obsessive compulsive beliefs and metacognitions. Statistical associations were also explored among obsessive compulsive and metacognitive belief domains in patients with OCD.

\section{RESULTS \& DISCUSSION}

Table 1: Socio demographic description of the sample

\begin{tabular}{|c|c|c|}
\hline Category & Clinical Sample $(n=20)$ & Non-Patient controls $(\mathrm{n}=20)$ \\
\hline \multicolumn{3}{|c|}{$\begin{array}{l}\text { Age } \\
\end{array}$} \\
\hline Mean & 27.5 & 28.15 \\
\hline S.D. & 7.48 & 9.29 \\
\hline \multicolumn{3}{|c|}{$\operatorname{Sex}[N(\%)]$} \\
\hline Male & $10(50)$ & $10(50)$ \\
\hline Female & $10(50)$ & $10(50)$ \\
\hline \multicolumn{3}{|c|}{ Education $[\mathrm{N}(\%)]$} \\
\hline $0-12$ & $6(30)$ & $2(10)$ \\
\hline $12 \&$ above & $14(70)$ & $18(90)$ \\
\hline \multicolumn{3}{|c|}{ Occupation [N(\%)] } \\
\hline Students & $7(35)$ & $9(45)$ \\
\hline Housewife & $2(10)$ & $2(10)$ \\
\hline Professionals & $5(25)$ & $9(45)$ \\
\hline Non-Professionals & $2(10)$ & ---- \\
\hline Unemployed & $4(20)$ & --- \\
\hline \multicolumn{3}{|c|}{ Marital status [N(\%)] } \\
\hline Single & $14(70)$ & $15(75)$ \\
\hline Married & $6(30)$ & $5(25)$ \\
\hline
\end{tabular}


Table 2: Comparison of scores among the two groups on OBQ-44 and MCQ-30

\begin{tabular}{|c|c|c|c|c|c|}
\hline & \multicolumn{2}{|c|}{$\begin{array}{l}\text { Clinical Sample } \\
\quad(\mathrm{n}=20)\end{array}$} & \multicolumn{2}{|c|}{$\begin{array}{l}\text { Non-Patient controls } \\
\qquad(\mathrm{n}=20)\end{array}$} & \multirow[b]{2}{*}{ t-values } \\
\hline & Mean & S.D. & Mean & S.D. & \\
\hline \multicolumn{6}{|c|}{ OBQ-44 } \\
\hline $\begin{array}{l}\text { Responsibility \& } \\
\text { Threat estimation }\end{array}$ & 79.10 & 19.47 & 43.30 & 18.20 & $6.00 * *$ \\
\hline $\begin{array}{c}\text { Perfectionism \& } \\
\text { Intolerance for uncertainty }\end{array}$ & 85.50 & 15.92 & 70.45 & 12.56 & $3.31^{*}$ \\
\hline $\begin{array}{c}\text { Importance \& } \\
\text { Control of thoughts } \\
\end{array}$ & 63.75 & 11.49 & 33.85 & 9.85 & $8.83^{* *}$ \\
\hline \multicolumn{6}{|c|}{ MCQ-30 } \\
\hline Positive Beliefs about worry & 15.30 & 6.02 & 12.30 & 4.30 & $1.81^{*}$ \\
\hline $\begin{array}{c}\text { Negative Beliefs about } \\
\text { uncontrollability \& danger of } \\
\text { thoughts }\end{array}$ & 20.10 & 3.71 & 10.95 & 4.45 & $7.05^{\star *}$ \\
\hline Cognitive confidence & 11.50 & 4.45 & 8.10 & 3.95 & $2.55^{*}$ \\
\hline Need for Control & 19.54 & 4.21 & 12.20 & 4.21 & $5.44^{* *}$ \\
\hline Cognitive-self consciousness & 18.80 & 3.44 & 11.80 & 4.36 & $5.63^{* *}$ \\
\hline
\end{tabular}

${ }^{*} \mathrm{p}<0.05 ;{ }^{* *} \mathrm{p}<0.01$. (Unpaired $t$ test used in the analysis)

Table 3: Correlations between scores on OBQ-44 \& Y-BOCS and MCQ-30 \& Y-BOCS (Clinical sample)

\begin{tabular}{|c|c|c|}
\hline \multirow{2}{*}{ Subscales } & \multicolumn{2}{|c|}{ Y-BOCS } \\
\cline { 2 - 3 } OBQ-44 & Obsessions & Compulsions \\
\hline \multicolumn{2}{|c|}{ MCQ-30 } \\
\hline Responsibility \&Threat estimation & $0.54^{*}$ & $0.54^{*}$ \\
\hline Perfectionism \& Intolerance for uncertainty & 0.41 & 0.44 \\
\hline Importance \& Control of thoughts & $0.47^{*}$ & $0.46^{*}$ \\
\hline Positive Beliefs about worry & $0.48^{*}$ & $0.45^{*}$ \\
\hline $\begin{array}{c}\text { Negative Beliefs about uncontrollability } \\
\text { \& danger of thoughts }\end{array}$ & 0.29 & 0.27 \\
\hline Cognitive confidence & 0.37 & 0.27 \\
\hline Need for Control & $0.45^{*}$ & 0.43 \\
\hline Cognitive-self consciousness & 0.40 & 0.32 \\
\hline
\end{tabular}

${ }^{*} \mathrm{p}<0.05 ;{ }^{* *} \mathrm{p}<0.01$

In terms of the socio-demographic profile, the clinical patient and non-patient groups were comparable in age, years of education and socioeconomic strata. The sample was representative of a young adult, urban population of students and working professionals, typical of the clinical presentation seen in the setting of the study. The clinical sample and the non-patient controls had an equal number of males and females (Table 1).

Observations on the presence of obsessive compulsive beliefs in samples of the study indicate that the clinical patients group scored significantly higher than non-patient controls on all domains of OBQ-44 namely (a) Responsibility and threat estimation (b) Perfectionism \& Intolerance for uncertainty and (c) Importance \& Control of thoughts (Table 2). These results are consistent with the previous research on 
obsessive compulsive beliefs of responsibility and threat estimation [51-53], Perfectionism \& Intolerance for uncertainty [51,53-54] and Importance \& Control of thoughts [51-53,55] which were significantly endorsed and exhibited by patients with OCD in comparison to non-patient controls. Further the clinical group also scored significantly higher on all domains of MCQ-30. The study observations are consistent with the existing research literature that indicates a range of metacognitive beliefs endorsed highly by OCD patients [56-59].

Correlation analysis for evaluation of associations between obsessive compulsive symptomatology, obsessive compulsive beliefs and metacognitions indicated positive and significant correlations between obsessive belief domains of responsibility \& threat estimation and Importance \& Control of thoughts with severity of obsessions and compulsions (Table 3). The current findings are consistent with the previous findings that have found a relationship between these belief domains and obsessive and compulsive symptoms [53,57,60-62]. In addition, they provide further evidence of predictions made by existing cognitive theories.

Correlational observations also indicate existence of positive and significant correlations between metacognitive belief domains of positive beliefs about worries with obsessions and compulsions and need for control of thoughts with obsessions (Table 3). These findings are consistent with the previous findings that too have found a relationship between these metacognitive beliefs and obsessions and compulsions [56-58, 63-65]. In addition, the metacognitive domain of importance/need for control of thoughts has been indicated as a factor which reliably predicts obsessions and neutralizing behaviors [62]. In other studies, only obsessions have been related to importance/ need for control of thoughts $[61,63,66]$. This research data provides growing support for the metacognitive model of OCD [24-25].

Table 4: Correlations between scores on OBQ-44 and MCQ-30 (Clinical sample)

\begin{tabular}{|c|c|c|c|}
\hline \multicolumn{2}{|c|}{ Subscales } & \multicolumn{3}{|c|}{ OBQ-44 } \\
\cline { 2 - 4 } & $\begin{array}{c}\text { Responsibility } \\
\text { \&Threat } \\
\text { estimation }\end{array}$ & $\begin{array}{c}\text { Perfectionism \& } \\
\text { Intolerance for } \\
\text { uncertainty }\end{array}$ & $\begin{array}{c}\text { Importance \& } \\
\text { Control of } \\
\text { thoughts }\end{array}$ \\
\hline \multicolumn{3}{|c|}{ MCQ-30 } & $0.52^{*}$ \\
\hline Negative Beliefs about uncontrollability \& \\
danger of thoughts & $0.67^{* *}$ & $0.64^{* *}$ & $0.75^{* *}$ \\
\hline Cognitive confidence & $0.73^{* *}$ & $0.75^{* *}$ \\
\hline Need for Control & 0.44 & $0.83^{* *}$ & $0.62^{* *}$ \\
\hline Cognitive-self consciousness & $0.69^{* *}$ & 0.39 & $0.72^{* *}$ \\
\hline
\end{tabular}

In this cross sectional exploration, positive and significant correlational associations were observed among certain subscales of OBQ-44 and MCQ-30. The correlations were evident namely among (a) Responsibility and threat estimation with: Positive beliefs about worry; with negative beliefs about uncontrollability and danger of thoughts and with need for control; (2) Perfectionism \& Intolerance for uncertainty with: Positive Beliefs about worry, with Negative Beliefs about uncontrollability \& danger of thoughts and with Need for Control over thoughts; (3) Importance \& Control of thoughts with Positive Beliefs about worry, with Negative Beliefs about uncontrollability \& danger of thoughts, with Cognitive confidence and with Need for Control over thoughts (Table 4). Thus, positive and significant correlations between most domains of metacognitive and obsessive compulsive beliefs were observed. The review of literature in this research area did not reveal studies which have investigated this relationship. These findings add to the growing evidence of interaction between metacognitive beliefs and obsessive compulsive beliefs as earlier postulated in metacognitive model of OCD [24-25]. We hypothesize that continuing efforts at exploring relationships between obsessive compulsive beliefs and metacognitive belief domains may provide 
increasing clarity into a specific cognitive-metacognitive profile for OCD, which would aid in facilitating the assessment of cognitive beliefs and its management through metacognitive and cognitive treatment strategies.

A heterogeneous sample and a small sample size were some of the study's limitations, which offered a limited understanding of metacognitions and its relationship with obsessive compulsive phenomena and obsessive compulsive beliefs. A longitudinal design may be more informative in terms of assessing changes in metacognitive domains occurring while undergoing psychotherapeutic treatment. This study was a preliminary effort to study metacognitions and its role in etiology of obsessive compulsive disorder. Furthermore, being an exploratory study, drawing the definitive conclusions from these findings may be premature. However, this may be extended to a larger study with a homogenous sample.

\section{CONCLUSION}

The results of this research study provide data on cross-sectional relationships between obsessive compulsive cognitive beliefs, metacognitive beliefs (S-REF Model) and obsessive compulsive symptoms in an Indian sample. The metacognitions along with obsessive compulsive cognitive beliefs are gradually proving to be significant to understanding of etiology of OCD. The present study highlights the need for more detailed research evaluation of this construct in patients with OCD. The findings have implications for treatments that focus on metacognitive belief modification to effect changes in obsessive and compulsive symptoms. In future studies, it would be appealing to explore the function of thought-fusions, beliefs about rituals, stop signals within the framework of metacognitive model of obsessive compulsive symptoms. Further role of positive beliefs about worry and cognitive confidence can also be evaluated.

\section{REFERENCES}

1. Karno M, Glodberg JM. Obsessive compulsive disorder, in: Robins LN, Regier DA, Editors. Psychiatric disorders in America: the epidemiologic catchment area study. The Free Press. New York, 1991; 204-19.

2. Weissman MM, Bland RC, Canino GJ, Greenwald S, Hwu HG, Lee CK, Newman SC, Oakley-Browne MA, Rubio-Stipec M, Wickramaratne PJ. The cross national epidemiology of obsessive compulsive disorder. J Clin Psychiatry 1994;55(Suppl 1):5-10.

3. Steketee G. Disability and family burden in obsessive-compulsive disorder. Can J Psychiatry 1997;42:91928.

4. World Health Organization. The "Newly Defined" Burden of Mental Problems. Geneva, Switzerland. 1999; Fact Sheets no. 217.

5. Greist JH, Jefferson JW, Kobak KA, Katzelnick DJ, Serlin RC. Efficacy and tolerability of serotonin transport inhibitors in obsessive compulsive disorder: A meta analysis. Arch Gen Psychiatry 1995;52:53-60.

6. Mancebo MC, Eisen JL, Pinto A, Greenberg BD, Dyck IR, Rasmussen SA. The Brown Longitudinal Obsessive Compulsive Study: treatments received and patient impressions of improvement. J Clin Psychiatry 2006;67:1713-20.

7. Pallanti S, Hollander E, Bienstock C, Koran L, Leckman J, Marazziti D, Pato M, Stein D, Zohar J. International Treatment Refractory OCD Consortium. Treatment non-response in OCD: Methodological issues and operational definitions. Int J Neuropsychopharmacol 2002;5:181-91.

8. Kozak MU, Liebowitz ML, Foa EB. Cognitive behavior therapy and pharmacotherapy for OCD. Goodman WK, Rudorfer M, Maser JD, Editors. Obsessive-Compulsive Disorder. Lawrence Erlbaum Associates; Mahwah, New Jersey, 2000;501-23.

9. Pigott TA, Seay SM. A review of the efficacy of selective serotonin reuptake inhibitors in obsessive compulsive disorder. J Clin Psychiatry 1999;60:101-6.

10. Rasmussen SA, Eisen JL, Pato MT. Current issues in pharmacological management of obsessivecompulsive disorder. J Clin Psychiatry 1993; 54( suppl 1):4-9.

11. Abramowitz JS. Effectiveness of psychological and pharmacological treatments for obsessive-compulsive disorder: a quantitative review. J Consult Clin Psychol 1997;65:44-52.

12. Foa EB, Liebowitz MR, Kozak MJ, Davies S, Campeas R, Franklin ME, Huppert JD, Kjernisted K, Rowan $\mathrm{V}$, Schmidt AB, Simpson HB, Tu X. Treatment of obsessive compulsive disorder by exposure and ritual 
prevention, clomipramine, and their combination: A randomized, placebo controlled trial. Am J Psychiatry 2005;162:151-61.

13. Greist JH. Behavior therapy for obsessive compulsive disorder. J Clin Psychiatry 1994;55(suppl):60-8.

14. Perse T. Obsessive-compulsive disorder: a treatment review. J Clin Psychiatry 1988;49:48-55.

15. Foa EB, Grayson JB, Steketee GS, Doppelt HG, Turner RM, Latimer PR. Success and failure in the behavioral treatment of obsessive compulsive disorder. J Consult Clin Psychol 1983;51:287-97.

16. Kobak KA, Greist JH, Jefferson JW, Katzelnick DJ, Henk HJ. Behavioral versus pharmacological treatments of obsessive compulsive disorder: a meta-analysis. Psychopharmacol 1998;136:205-16.

17. Lucey JV, Butcher G, Clare AW. The clinical characteristics of patients with obsessive compulsive disorders: a descriptive study of an Irish sample. Int J Psychol Med 1994;11:11-4.

18. Jacobi DM, Calamari JE, Woodar JL. Obsessive compulsive disorder beliefs, meta-cognitive beliefs and obsessional symptoms: relations between parent beliefs and child symptoms. Clin Psychol Psychotherapy 2006;13:153-62.

19. Salkovskis PM. Obsessional compulsive problems: a cognitive behavioural analysis. Behav Res Ther 1985; 23:571-83.

20. Salkovskis PM. Cognitive behavioral factors and persistence of intrusive thoughts in obsessional problems. Behav Res Ther 1989;27:677-82.

21. Rachman S. A cognitive theory of obsessions. Behav Res Ther 1997;35:793-802.

22. Rachman S. A cognitive theory of obsessions: elaborations. Behav Res Ther 1998;36:385-401.

23. Purdon CL, Clark DA. Metacognition and Obsessions. Clin Psychol and Psychother 1999;6:102-10.

24. Wells A, Matthews G. Attention and emotion: a clinical perspective. Hove, United Kingdom: Lawrence Erlbaum Associates; 1994.

25. Wells A. Cognitive therapy of anxiety disorders: a practice manual and conceptual guide. Chichester, United Kingdom: Wiley; 1997.

26. Rachman S, Thordarson DS, Shafran R, Woody SR. Perceived responsibility: structure and significance. Behav Res Ther 1995;33:779-84.

27. Shafran R, Thordarson DS, Rachman S. Thought-action fusion in obsessive compulsive disorder. J Anxiety Disord 1996;10:379-91.

28. Calamari JE, Janeck AS. Intrusive thought in obsessive compulsive disorder: appraisal differences. Depress Anxiety 1998;7:139-40.

29. Wells, A. Emotional disorders and metacognition: innovative cognitive therapy. Chichester, United Kingdom: Wiley; 2000.

30. Myers SG, Fisher PL, Wells A. Metacognition and cognition as predictors of Obsessive -compulsive symptoms: A prospective study. Int J Cogn Ther 2009;2:107-22.

31. Wells A, Mathews G. Modelling cognition in emotional disorder: the S-REF model. Behav Res Ther 1996; 34:881-8.

32. Fenigstein A, Scheier MF,Buss AH. Public and private self-consciousness: assessment and theory. J Consul Clin Psychol 1975;43:522-7.

33. Ingram R. Self-focused attention in clinical disorders: review and conceptual model. Psych Bull 1990; 107:156-76.

34. Carver CS, Blaney PH, Scheier MF. Focus of attention, chronic expectancy, and responses to a feared stimulus. J Personal Soc Psychol 1979;37:1186-95.

35. Rachman S, Lopatka C, Levitt K. Experimental analyses of Panic:II.Panic patients. Behav Res Ther 1998; 26:33-40.

36. Cartwright-Hatton S, Wells A. Beliefs about worry and intrusions: The Meta-Cognitions Questionnaire and its correlates. J Anxiety Disord 1997;11:279-96.

37. Janeck AS, Calamari JE, Riemann BC, Heffelfinger SK. Too much thinking about thinking?: metacognitive differences in obsessive-compulsive disorder. J Anxiety Disord 2003;17(2):181-95.

38. Marker CD, Calamari JE, Woodard JL, Riemann, BC. Cognitive self-consciousness, implicit learning and obsessive compulsive disorder. J Anxiety Disord 2006;20:389-407.

39. Rauch SL, Savage CR. Investigating cortico-striatal pathophysiology in obsessive-compulsive disorders: procedural learning and imaging probes. In: WK Goodman, MV Rudorfer. Editors. Obsessive-compulsive disorder: contemporary issues in treatment. Mahwah, New Jersey: Lawrence Erlbaum Associates, Publishers. 2000; pp.133-54.

40. Goldman BL, Martin ED, Calamari JE, Woodard JL, Chik HM, Messina MG, Pontarelli NK, Marker CD, Riemann BC, Wiegartz PS. Implicit learning, thought-focused attention and obsessive-compulsive disorder: a replication and extension. Behav Res Ther 2008;46(1):48-61.

41. Clark DA. Cognitive behavior therapy of OCD. New York: Guilford Press. 2004. 
42. Frost RO, Steketee G. Cognitive approaches to obsessions and compulsions: theory,assessment and treatment. Oxford: Pergamon. 2002.

43. Saxena S, Rauch SR. Functional neuroimaging and the neuroanatomy of obsessive-compulsive disorder. Psychiatr Clin North Am 2000;23:563-86.

44. Goldberg DP. The Detection of Psychiatric Illness by Questionnaire. Oxford University Press, London. 1972.

45. Goldberg DP, Williams PA. A User's Guide to the Windsor. NFER-Nelcon Publishing Company, United Kingdom. 1988.

46. Goodman WK, Price LH, Rasmussen SA, Mazure C, Fleischmann RL, Hill CL, Heninger GR, Charney DS. The Yale-Brown Obsessive Compulsive Scale: II. Development, use, and reliability. Arch Gen Psych 1989;46:1006-11.

47. Steketee G, Frost R, Bogart K. The Yale-Brown Obsessive Compulsive Scale: interview versus self-report. Behav Res Ther 1996;34:675-84.

48. Obsessive Compulsive Cognition Working Group (OCCWG). Psychometric validation of the Obsessive Beliefs Questionnaire and the Interpretation of Intrusions Inventory: Part 2: factor analyses and testing of a brief version. Behav Res Ther 2005;43:1527-42.

49. Tolin DF, Worhunsky P, Maltby N. Are "obsessive" beliefs specific to OCD?: a comparison across anxiety disorders. Behav Res Ther 2006;44:469-80.

50. Wells A, Cartwright-Hatton S. A short form of the metacognitions questionnaire: properties of the MCQ 30. Behav Res Ther 2004;42:385-96.

51. Steketee G, Frost RO, Cohen I. Beliefs in obsessive compulsive disorder. J Anxiety Disord 1998;12:525-37.

52. Salkovskis PM, Wroe AL, Gledhill A, Morrison N, Forrester E, Richards C, Reynolds M, Thorpe S. Responsibility attitudes and interpretations are characteristic of obsessive compulsive disorder. Behav Res Ther 2000;38:347-72.

53. Obsessive Compulsive Cognition Working Group (OCCWG). Development and initial validation of the Obsessive Beliefs Questionnaire and the Interpretation of Intrusions Inventory. Behav Res Ther 2001;39: 987-1006.

54. Frost RO, Steketee G. Perfectionism in obsessive compulsive disorder patients. Behav Res Ther 1997;35: 291-6.

55. Amir N, Cashman L, Foa EB. Strategies of thought control in obsessive compulsive disorder. Behav Res Ther 1997;35:775-7.

56. Wells A, Papageorgiou C. Relationships between worry, obsessive compulsive symptoms and meta-cognitive beliefs. Behav Res Ther 1998;36:899-913.

57. Myers SG, Wells A. Obsessive compulsive symptoms: the contribution of metacognitions and responsibility. J Anxiety Disord 2005;19:806-17.

58. Garcia-Montes JM, Perez-Alvarez M, Balbuena CS, Garcelan SP, Cangas AJ. Metacognitions in patients with hallucinations and obsessive compulsive disorder: The superstition factor. Behav Res Ther 2006;44: 1091-1104.

59. Irak M, Tosun A. Exploring the role of metacognition in obsessive compulsive and anxiety symptoms. J Anxiety Disord 2008;22:1316-25.

60. Purdon CL, Clark DA. The need to control thoughts, in: Frost RO, Steketee G. Editors. Cognitive approaches to obsessions and compulsions: theory, assessment and treatment. Oxford, United Kingdom. Elsevier, 2002; 29-43.

61. Tolin DF, Woods CM, Abramowitz JS. Relationship between obsessive beliefs and obsessive compulsive symptoms. Cogn Ther Res 2003;27:657-69.

62. Myers SG, Fisher PL, Wells A. Belief domains of the Obsessive Beliefs Questionnaire-44 (OBQ-44) and their specific relationship with obsessive compulsive symptoms. J Anxiety Disord. 2008; 22:475- 84 .

63. EmmelKamp PMG, Aardema A. Metacognitions specific obsessive compulsive beliefs, and obsessive compulsive behaviour. Clin Psychol Psychother 1999;6:139-45.

64. Hermans D, Martens K, De Cort K, Pieters G, Eelen P. Reality monitoring and meta-cognitive beliefs related to cognitive confidence in obsessive compulsive disorder. Behav Res Ther 2003;41:383-401.

65. Gwilliam P, Wells A, Cartwright-Hatton S. Does metacognition or responsibility predict obsessive compulsive symptoms? A test of the meta-cognitive model. Clin Psychol Psychother 2004;11:137-44.

66. Julien D, O'Connor KP, Aardema F, Todorov C. The specificity of belief domains in obsessive-compulsive symptom subtypes. Personal Individ Diff 2006;41:1205-16.

Acknowledgements - We would like to thank Dr.Priya Kayastha Anand, Consultant Clinical Psychologist for providing useful suggestions on this manuscript; Funding - Nil; Conflict of Interest - Nil. 